\title{
AS CONDIÇÕES DE PRODUÇÃO DO MOBILIÁRIO MINEIRO NO SÉCULO XVIII E INÍCIO DO XIX
}

KARINA RIBEIRO DE OLIVEIRA, UNIVERSIDADE DE SÃO PAULO, SÃO PAULO, SÃO PAULO, BRASIL. Mestranda do Programa de Pós-Graduação em Arquitetura e Urbanismo da Faculdade de Arquitetura e Urbanismo da Universidade de São Paulo, SP, Brasil, com pesquisa financiada pelo CNPq.

E-mail: karina.ribeiro@usp.br

ANDREA BUCHIDID LOEWEN, UNIVERSIDADE DE SÃO PAULO, SÃO PAULO, SÃO PAULO, BRASIL. Professora do Departamento de História da Arquitetura e Estética do Projeto da Faculdade de Arquitetura e Urbanismo da Universidade de São Paulo, SP, Brasil.

E-mail: andrealoewen@usp.br

DOI

http://dx.doi.org/10.11606/issn.1980-4466.v0i23p149-169 


\section{AS CONDIÇÕES DE PRODUÇÃO DO MOBILIÁRIO MINEIRO NO SÉCULO XVIII E INÍCIO DO XIX \\ KARINA RIBEIRO DE OLIVEIRA, ANDREA BUCHIDID LOEWEN}

\section{RESUMO}

O presente artigo discute o trabalho dos artífices e o ambiente de produção artística na região de Minas Gerais no século XVIII e início do XIX, com ênfase nas questões que tiveram reflexo na produção do mobiliário originário daquela região.

\section{PALAVRAS-CHAVE}

Mobiliário colonial. Minas Gerais. Produção de mobiliário. 
THE CONDITIONS OF PRODUCTION OF THE FURNITURE FROM MINAS GERAIS IN THE EIGHTEENTH CENTURY

\section{AND EARLY NINETEENTH}

KARINA RIBEIRO DE OLIVEIRA, ANDREA BUCHIDID LOEWEN

\section{ABSTRACT}

This article discusses the work of the crafters and the artistic production environment in the region of Minas Gerais in the Eighteenth and early Nineteenth centuries, with emphasis on the issues that had repercussions in the production of the furniture originating from that region.

\section{KEYWORDS}

Colonial Furniture. Minas Gerais. Furniture Production. 


\section{INTRODUÇÃO}

O estudo do mobiliário no contexto da América portuguesa tem sido beneficiado, desde a constituição do Serviço do Patrimônio Histórico e Artístico Nacional (SPHAN), em 1937, pela instalação de arquivos e museus em cujos acervos se abrigam documentos e objetos relacionados à esfera da vida privada, elementos que contribuíram para a preservação dos poucos bens móveis antigos remanescentes no Brasil dos primeiros séculos e seu respectivo inventariado. Tais reminiscências têm possibilitado uma série de análises e fundamentações, desde os estudos pioneiros, como o de Lúcio Costa (1939) - que demarcava em suas "Notas" três grandes períodos na história do móvel brasileiro, compreendendo os elementos de origem portuguesa e as assimilações europeias e orientais (mouras e indianas) sem, contudo, se ater a classificações estilísticas vinculadas aos "gostos" dos monarcas e também sem se debruçar sobre o problema da identificação do móvel brasileiro com características próprias -, ou o de José de Almeida Santos (1944) - que a partir de visitas a museus, igrejas e coleções particulares, de Norte a Sul do Brasil, e de leituras de documentos e textos literários, principiou uma discussão mais abrangente em torno da identidade do móvel brasileiro em oposição à mera cópia dos modelos portugueses —, passando pelo de José Washt Rodrigues (1968) - que se dedicava à observação direta das peças de mobiliário para estabelecer cri- 
térios formais para a compreensão visual e identificação dos "estilos" em suas formas e ornatos - , até os mais recentes, que buscam compreender as implicações dos antigos ofícios relacionados ao trabalho em madeira no contexto luso-brasileiro. Entre estes últimos, destacam-se os de Maria Helena Flexor $(1974,1978,2009)$ - que inventaria o mobiliário usado na Bahia, sobretudo em Salvador, do início do século XVIII até meados do século XIX, tratando dos ditos estilos, dos materiais empregados em sua confecção e, com particular interesse, dos aspectos relativos à mão de obra, aos ofícios mecânicos —, assim como o de Tilde Canti (1980) que, adotando metodologia semelhante à de Flexor, porém com abordagem distinta, estende sua análise para o conjunto dos exemplares brasileiros, procurando demarcar certas características de cunho regionalista em meio à variedade de filiações artísticas identificadas no mobiliário presente em coleções particulares e acervos de museus e instituições religiosas.

Em vista desta premissa, que toma o móvel como parte integrante de uma complexa rede de relações e assume as particularidades da produção do mobiliário e suas implicações na história social e na "cultura material", o presente artigo procura estabelecer certas balizas para a compreensão do móvel no contexto específico das Minas do século XVIII e início do XIX, para além da análise formal de peças remanescentes (ou de fontes de documentação primária) e das tentativas de classificações e descrições estilísticas, apoiando-se para isto em uma peculiar articulação da historiografia, de modo a possibilitar outros desdobramentos e os necessários aprofundamentos sobre o tema.

\section{PRODUÇÃO ARTÍSTICA NA REGIÃO DE MINAS GERAIS}

As investigações relativas ao estudo dos ofícios na região mineira têm se valido em grande medida do Dicionário de artistas e artífices dos séculos XVIII e XIX em Minas Gerais, organizado por Judith Martins (1974) e publicado pelo Instituto do Patrimônio Histórico e Artístico Nacional (Iphan) a partir de levantamentos feitos por diversos pesquisadores.

Partindo de tais bases, Cybele Fernandes (2007) procura, em seu estudo, não apenas reunir dados sobre a procedência e a formação dos profissionais, mas investigar as regiões de Portugal que exerceram maior influência na produção dos artistas e artífices mineiros e: 
[...] estabelecer relação comparativa entre a formação e produção dos artistas e artífices de origem portuguesa e brasileira, a fim de compreender melhor as questões de produção e as tendências estilísticas que permeiam o acervo dessa região (FERNANDES, 2007, p. 112).

A existência de uma relação entre a origem dos profissionais portugueses e as características formais observadas em suas produções artísticas em Minas Gerais também é considerada por Myriam de Oliveira (2007, p. 429) que, ao analisar retábulos presentes em edifícios religiosos, identifica uma clara diferenciação estilística entre as peças produzidas por entalhadores de origem bracarense e aqueles lisboetas. Em seu entendimento, existiria uma constante predominância de aspectos ornamentais nas obras dos primeiros, ao passo que naquelas produzidas pelos segundos prevaleceriam os aspectos escultóricos, com ênfase na representação das figuras humanas.

Neste sentido, cabe ampliar a discussão sobre o papel dos ofícios e do trabalho artístico na região mineira naquele período, de modo a contribuir à análise do mobiliário presente em Minas Gerais nos Setecentos e princípios dos Oitocentos, bem como à investigação da possível existência de características regionais nas peças que, pertencentes a este conjunto, são comumente tidas como de origem mineira.

Em princípios do século XVIII, com o advento da mineração, diversos oficiais e artesãos paulistas se transferiram das vilas vicentinas para a região das Minas em busca de novas oportunidades de trabalho e uma maior proximidade com novos clientes. Entre estes se encontravam ferreiros, alfaiates, sapateiros, oleiros, padeiros, marceneiros, cantoneiros e outros (ZEMELLA, 1990, p. 59). Mas, junto às sucessivas levas de paulistas, também baianos partiram para povoar Minas e "esse novo ciclo econômico, surgido justamente no início da decadência da agroindústria açucareira, veio a ter importantes repercussões na prática de ofícios manufatureiros" (CUNHA, 2000, p. 35).

Embora de início tenha se estabelecido nas zonas mineradoras uma grande quantidade de paulistas e indivíduos "brancos e mestiços, reinóis e nortistas" vindos da Bahia, a corrente de maior vulto que se dirigiu às Minas Gerais se constituiu de emigrados de Portugal e de outras regiões 
europeias nas quais predominavam cristãos novos ou judeus vindos da Holanda. Mas, assim como aqueles primeiros grupos, nem todos se dedicavam ao trabalho da mineração; havia, além dos mercadores fixos ou ambulantes, uma grande quantidade de artífices, além de pedreiros, carpinteiros, entalhadores e ourives, entre outros que se estabeleceram nos novos povoados (LIMA JÚNIOR, 1978, p. 75).

Na primeira metade do século XVIII, cerca de 800 mil pessoas partiram de Portugal para as Minas; quase a metade da população do reino. Estes, de caráter menos inquieto, assim como o dos demais brasileiros chegados mais tarde a Minas Gerais, promoveram o posterior desenvolvimento da região (VASCONCELLOS, 2011, p. 16-20).

A peculiar conformação dos povoados em Minas e sua grande distância em relação ao litoral promovia uma situação de dependência dos mineradores em relação à presença de artífices, artesãos e comerciantes instalados na região, de forma que os preços cobrados por tais profissionais se tornavam frequentemente sobrevalorizados.

O isolamento em relação ao litoral povoado e o exclusivismo das atividades humanas proporcionam também a valorização do trabalho livre, sendo de tal modo caro o concernente às construções que causa espécie ao autor do Diário da Jornada que fez o Exmo. Sr. D. Pedro, desde o Rio de Janeiro até a cidade de S. Paulo e desta até a Minas - ano de 1717. Referindo-se à casa mandada construir para receber o Governador, em Vila Rica, espanta-se "que a muito valor em Lisboa poderiam custar seis para sete mil cruzados" ao passo que, a Henrique Lopes, seu proprietário, "estiveram em quarenta e cinco" (Ibidem, p. 56).

Num aprofundado estudo sobre a estrutura populacional segundo ofícios e atividades produtivas no início do século XIX, em Vila Rica, Costa e Luna (1982, p. 65-77) elucidam que 53,61\% da população se dedicavam a atividades do setor secundário - na condição de armeiros, funileiros, carpinteiros, fundidores, ferradores (sendo essas atividades exclusivamente masculinas), costureiras, doceiras, fiandeiras, rendeiras, tecedeiras (profissões de predominância feminina), entre outras. Esta porcentagem nos permite vislumbrar a grande parcela da população constituída por artífices, mesmo após a virada do século. 
Ao analisar uma crônica elaborada em 1790, pelo capitão Joaquim José da Silva, sobre a situação das artes em Minas Gerais, com ênfase na arquitetura e na escultura, Myriam de Oliveira (2007) reitera uma significativa presença de profissionais portugueses na região mineira. A autora afirma que, entre vários nomes de arquitetos e artistas mencionados no documento do Vereador de Mariana, é provável que Antônio Francisco Lisboa seja o único efetivamente nascido no Brasil. Os demais seriam, em sua maioria, de origem portuguesa. Os construtores e mestres de obras são procedentes, ao menos aqueles cuja origem se pode estabelecer, sobretudo do arcebispado de Braga, de Lisboa e do Porto. Já no que se refere aos entalhadores e escultores, "todos são bracarenses ou lisboetas entre as procedências conhecidas" (OLIVEIRA, 2007, p. 423).

A partir dos levantamentos do referido "Dicionário" de Judith Martins, Cybele Fernandes (2007, p. 113) nota tanto a existência de algumas oficinas de famílias, como aquela de "João G. Rosa, Manuel Antônio G. Rosa e Manuel José da Rosa, carpinteiros, ativos em Congonhas do Campo", como a tradição da continuidade do trabalho de um mestre pelos seus escravos. Em sua análise, a transferência de portugueses para a região das Minas, onde puderam contribuir com seu trabalho, repercute também, mesmo que de forma incipiente, na formação de artesãos e artistas locais.

O fato de a maioria dos artífices e mestres de ofício portugueses ativos em Minas Gerais no século XVIII ser oriunda do norte de Portugal se deve, em parte, às dificuldades sociais e econômicas enfrentadas naquela região desde o início dos Setecentos. Um grande número de indivíduos destituídos da herança da terra de seus pais buscava outras possibilidades de atividades, "como o artesanato, o comércio, o aprendizado nos ofícios mecânicos ou, mais raramente, para os mais bem dotados, a vida eclesiástica ou burocrática" (DANGELO, 2006, p. 274-275). A aprendizagem tradicional de ofícios se dava em oficinas nas quais os aprendizes eram treinados e frequentemente, mediante contrato, recebiam alojamento, vestuário e alimentação.

Terminado o tempo de aprendizado, ainda exigia-se do aprendiz, segundo os estatutos dos ofícios em Portugal, que o mesmo permanecesse na oficina do mestre como oficial durante seis anos, para enfim poder ser examinado por dois juízes do ofício que verificavam a sua 
competência, o que possibilitaria enfim abrir sua própria oficina e trabalhar para si mesmo. Esses longos anos como oficial vinculado à oficina do mestre têm sido apontados como um dos motivos da migração dos jovens oficiais para o Brasil, onde as regras e as oficinas, principalmente na nova região das Minas, carente destes profissionais, tinham normas menos rígidas quanto ao tempo de aprendizado e aos vínculos com o mestre, possibilitando, assim, maior rapidez para obtenção da Carta de Ofício. (DANGELO, 2006, p. 277)

Na Capitania de Minas Gerais no século XVIII, observa Jeaneth de Araújo (2005, p. 206), o ensino das artes e ofícios se dava no próprio canteiro de obras, local comum da atuação em parceria de artistas e artífices que, muitas vezes, levava à constituição de vínculos de parentesco.

A pouca idade com a qual os artistas imigravam para Minas Gerais - a maioria entre os seus 20 e 25 anos - explicaria, em parte, segundo Dangelo (2006, p. 277), a dificuldade de encontrar evidências de suas obras em Portugal. Até o ano de 1720, os emigrados portugueses e europeus eram quase exclusivamente homens solteiros. Estes se uniam a escravas africanas ou mulatas, promovendo um significativo aumento da população de pardos na região mineira. Mas ainda que estes filhos de europeus com africanas nascessem "europeus" na língua, nos costumes, na religião e mentalidade, reconhece-se em suas obras como artesãos, "mesmo no anonimato em que quase todas jazem", os "traços negroides" nas figuras dos santos pintados nos painéis, ainda que as características gerais de tais obras possam ser consideradas absolutamente europeias (LIMA JÚNIOR, 1978, p. 75-76).

No que concerne à regulamentação do trabalho dos oficiais na região mineira, o exame dos primeiros 130 livros do "Arquivo Colonial de Ouro Preto" empreendido por Salomão de Vasconcelos, com datas de 1711 a 1830, permite demarcar três tipos de processos de exercício dos ofícios mecânicos em Vila Rica:

O do trabalho livre, no começo da vida municipal, até mais ou menos 1725; o das licenças com fiador, por tempo que variava entre seis meses a um ano; e o das licenças mediante exame prévio dos candidatos e expedição das respectivas cartas de habilitação, estas, porém, em pequeno número [...] (VASCONCELOS, 1940, p. 331). 
O autor afirma que, embora fossem frequentes os editais convidando os profissionais a se submeterem aos exames, as licenças com fiador eram mais utilizadas, sendo que os exames eram mais frequentados por sapateiros, alfaiates e ferreiros. Situação semelhante ocorreria em outras regiões da América portuguesa nos Setecentos, pois, conforme elucida Maria Helena Flexor, em Salvador, entre os profissionais "naturais da terra" ou portugueses que haviam ali iniciado sua atividade mecânica, poucos teriam se submetido aos exames. "Grande parte dos marceneiros pedia simplesmente sua licença, pagando fiança para ter tenda aberta ou loja para vender móveis ou trastes usados" (FLEXOR, 2009, p. 52).

Meneses (2003, p. 254) menciona a questão do "trabalho livre" em Vila Rica até o ano de 1725 como uma interpretação de Salomão de Vasconcelos (1940), não desconsiderando a probabilidade de que o exercício "mais livre de regimentações internas ao próprio grupo de atividades congêneres, sem formalizações escritas, tenha sido uma rotineira forma de inserção na economia artesanal", ressaltando, porém, que "o trabalho mecânico, mesmo assim, não pôde ser taxado de livre das exigências restritivas típicas da regulamentação corporativa do mundo reinol” e, neste sentido, as Câmaras teriam atuado na busca de uma ordem interna dos trabalhos ${ }^{1}$.

Naquele contexto das Minas setecentistas, o acúmulo de tarefas por parte dos profissionais e sua especialização em mais de uma atividade era bastante comum. Embora os regimentos portugueses dos ofícios mecânicos procurassem determinar que cada profissional se ativesse somente a sua área de atuação, "no que dizia respeito aos limites e atribuições de cada ofício, tanto em Portugal quanto na Capitania de Minas Gerais, não existiu uma rígida observância desses limites" (ARAÚJO, 2005, p. 205). Novamente, este não parece ter sido um traço exclusivo da região mineira, já que também na Bahia, segundo Flexor (1978, p. 41), “a divisão das

1. Jeaneth de Araújo (2005, p. 204) também ressalta a necessidade de aprofundamentos sobre textos como o de Vasconcelos, que, embora fundamentais para a abordagem das artes e ofícios nas Minas, devem ser tomados como trabalhos datados, "produto da mentalidade da época em que foram escritos", e ainda passíveis de revisões, destacando que embora o autor intencione mencionar apenas os oficiais ativos na construção e ornamentação de templos, os nomes de muitos profissionais que deveriam constar no recorte proposto são faltosos em tais estudos. 
obras entre os marceneiros, carpinteiros, torneiros e entalhadores sempre foi muito mais teórica que realmente prática", tendo sempre havido intromissões de uns nas tarefas dos outros. Em Minas, a variedade de funções nas quais os profissionais se empregavam é exemplificada também pelos registros ligados a oficiais renomados, como Manuel Francisco Lisboa que, em 1724, obteve licença da Câmara para exercer o ofício de carpinteiro em Vila Rica e algum tempo depois já não era mencionado nos registros dentre os carpinteiros contribuintes, "provavelmente por já ter passado a desempenhar ofícios 'liberais' como o de arquiteto e escultor" (CUNHA, 2000, p. 37).

Os profissionais eram divididos de acordo com o material que utilizavam - fosse metal, pedra ou madeira - , e de acordo com cada material se subdividiam em categorias: serralheiros, ferreiros ou ourives, para aqueles que atuavam com o metal; canteiros ou pedreiros, para os trabalhos em pedra; carpinteiros, carapinas, marceneiros ou entalhadores, para os que trabalhavam a madeira (BRANDÃO, 2009, p. 52). Em seu estudo acerca do mobiliário baiano, Maria Helena Flexor lembra que

\footnotetext{
Vários oficiais mecânicos interferiam na confecção dos móveis, como os marceneiros ou carpinteiros de obras brancas e pretas, torneiros, entalhadores, carpinteiros de móveis e samblagem, correeiros lavradores de couro, picadores de sola ou couro, ferreiros ou serralheiros. A confecção de cadeiras, por exemplo, podia reunir marceneiros e correeiros. O marceneiro podia acumular a função de torneiro, mas não a de entalhador. O profissional dessa especialidade intervinha no móvel separadamente (FLEXOR, 2009, p. 39).
}

Com relação às "obras brancas" ou "pretas", as primeiras se referiam à “carpintaria de edifícios", ao passo que as segundas, à confecção de móveis (FLEXOR, 1978, p. 40)

Para melhor compreender a definição geral dos ofícios relacionados à madeira, convém recorrer ao Vocabulario portuguez e latino de Raphael Bluteau, organizado entre os anos de 1712 e 1728. No escrito, carpinteiro é definido como aquele que executa obras lisas de madeira (BLUTEAU, 1728 , v. 2, p. 158); ensamblador ou samblador, como o oficial "que obra, \& junta madeyra liza, \& a corta a meya esquadria” (Ibidem, v. 7, p. 464); en- 
talhador é o "official de obra de talha com flores de madeira, \& folhagens, com cabeças de Anjos [...], brutescos, \& outras figuras de meyo relevo [...]" (Ibidem, v. 3, p. 138); escultor o que executa figuras de madeira ou de pedra (Ibidem, v. 3, p. 234); e, por fim, marceneiro se refere ao profissional "que lavra madeira com mais primor que [o] Carpinteiro" (Ibidem, v. 5, p. 324).

$\mathrm{Na}$ documentação constante no dicionário de Judith Martins, que contempla cópias de originais de arquivos públicos de várias cidades mineiras e permite traçar um panorama da atuação de profissionais entre as décadas de 1720 a 1820, encontram-se termos usados à época para dar nome às funções que podem parecer ambíguos. A análise dos verbetes desta obra, realizada por Angela Brandão (2013, p. 403-405) destaca a referência a "375 carpinteiros, 65 entalhadores, mas a apenas 32 marceneiros", observando ainda "que grande maioria destes era nascida em Portugal e não havia passado por exame de ofício nas Câmaras de Minas Gerais". Ainda segundo a autora, é possível inferir "um sistema de equivalência em termos de atuação" a partir da observância do predomínio do ofício de carpinteiro. Além disso, em documentação associada a artífices da carpintaria se encontram registros de serviços de marcenaria.

Por exemplo, Pedro Machado Toledo, considerado carpinteiro, tem como único documento em seu nome um recibo pelo "feitio de 50 castiçais torneados", em 1794 [...]. Como esse, inúmeros exemplos remetem artífices da carpintaria a serviços de marcenaria, em lugar de construções maiores, de pontes e de outras grandes estruturas de madeira (BRANDÃO, 2009, p. 55-56).

Em mesma linha, ela cita o caso de Antônio José da Fonseca, mencionado como carpinteiro mas que executou, em 1760, balaústres para a Sé de Mariana e duas cadeiras de braços para a Casa de Fundição e Intendência dez anos mais tarde.

Também se adverte uma imbricação entre os campos de atuação de entalhadores e marceneiros, assim como a ocorrência de conflitos decorrentes dela. Nos autos de execução do "Litígio entre marceneiros e entalhadores no Rio de Janeiro (1759-1761) no Senado da Câmara do Rio de Janeiro", o entalhador Francisco Félix da Cruz foi acusado de atuar como 
marceneiro sem ter se submetido aos devidos exame e licença. A acusação se baseava numa regulamentação de Portugal, datada de 1748, que proibia a prática de distintos ofícios pelos profissionais. Entretanto, segundo outra regulamentação de 1741, "no caso particular do pintor e do escultor (e aí se inclui o entalhador) esses profissionais, por serem considerados liberais, não eram obrigados a tirarem as ditas licenças" (FERNANDES, 2007, p. 114).

Sobre tal imbricação dos campos de atuação dos diferentes ofícios, é interessante destacar o depoimento de Manuel de Araújo por ocasião do Litígio, citado por Cybele Fernandes:

Segundo esclareceu, por depoimento, Manuel de Araújo, entalhador português, anteriormente ativo em Lisboa e então com loja no Rio de Janeiro, essa obrigação era comum em Lisboa, mas com o fim exclusivo do acesso do entalhador à bandeira da irmandade dos marceneiros. A favor do entalhador, Manuel de Araújo esclareceu ainda que, no Brasil, inversamente, conhecia vários marceneiros que trabalhavam também como entalhadores. Observa-se ainda, nesse episódio, que sendo chamados a depor quinze profissionais, entre portugueses e brasileiros, os depoentes não deixaram dúvida sobre a posição elevada do ofício do entalhador perante os demais que trabalhavam com a madeira. À oficina do entalhador comumente recorriam merceneiros [sic], pedreiros, ourives, outros oficiais que precisassem de um risco ou modelo para suas obras, com a certeza de que seriam realizadas com correta base técnica e gosto decorativo. (FERNANDES, 2007, p. 114)

Que houvessem aproximações, que as distinções entre as áreas de atuação dos profissionais não fossem assim tão bem definidas, atesta-se pelo próprio conjunto de tarefas requeridas para o exame de qualificação dos oficiais. Segundo Brandão (2013), nos exames para pedreiro e carpinteiro, por exemplo, entre as habilidades exigidas para cada um, duas se correspondiam, pois ambos teriam que fazer uma escada e uma porta, embora trabalhassem com materiais diferentes. Essa similaridade de atividades também ocorria para o exame de ensambladores e entalhadores. Os primeiros "fariam um painel, com sua moldura, decorado com colunas dóricas, e, sobre as colunas, deveriam fazer um friso, com seus tríglifos, 
sua arquitrave e frontispício com proporções adequadas", ao passo que os segundos teriam que "realizar um friso com ornamentos romanos, muito bem ordenados" com a escultura de um serafim ao centro e mais um capitel coríntio (BRANDÃO, 2013, p. 398). A autora afirma que são raros os documentos com registros de escultores e pintores, no conjunto da documentação levantada para o "Dicionário" de Judith Martins, por estes não se submeterem ao mesmo tipo de "controle" a que estavam sujeitos os demais ofícios mecânicos.

\footnotetext{
A aprendizagem dos ofícios de escultor e pintor, os mais característicos do artesanato na economia mineira, não obedeciam aos regulamentos que se tentou impor aos ofícios mecânicos de Vila Rica (pedreiros, carpinteiros, ferreiros, alfaiates, ourives) e que tiveram vigência nos principais centros urbanos da Colônia. Não havia contratos escritos, número mínimo de aprendizes por mestre, nem outras restrições, estando as relações entre mestres e aprendizes muito mais livres, ou então, muito mais presas a outras relações (CUNHA, 2000, p. 37).
}

Brandão considera ainda que as Belas Artes e as artes mecânicas também se entrelaçavam, uma vez que os profissionais atuavam de acordo com as demandas apresentadas. Pedreiros, carpinteiros, ferreiros, entalhadores e pintores se ocupavam igualmente tanto nas encomendas para a construção de obras públicas, como chafarizes, pontes e edifícios diversos, como naquelas vinculadas à Igreja, na ereção e decoração de templos (CUNHA, 2000, p. 37).

A sobreposição de funções se expressava inclusive nas indicações dos serviços a serem realizados. "Tal diversidade os levava, muitas vezes, de grandes empreitadas a pequenos e delicados serviços de marcenaria, [...] das madeiras lisas às torneadas e entalhadas, das pontes aos anjos e castiçais" (BRANDÃO, 2013, p. 412). Os registros de atividades de um mesmo profissional em diferentes funções, indistintamente, indicam ser este um traço característico da época, quando os exercícios nos mais diversos serviços acabavam por contribuir para a destreza e capacitação dos oficiais para distintas funções em áreas afins (FERNANDES, 2007, p. 112). A exemplo disto, Jeaneth de Araújo esclarece que o termo

[...] "pintor" podia abranger desde o simples artífice que encarnava e estofava imagens, pintava bandeiras, ou outros objetos, como tam- 
bém podia nomear os peritos na arte da pintura, especializados em policromar os forros das naves e capelas-mores das igrejas ou capelas (ARAÚJO, 2005, p. 205-206).

A autora acrescenta ainda que, na região mineira, o trabalho de douramento (por meio da aplicação de folhas de ouro) era exercido pelos pintores, exemplificando que mesmo um profissional reconhecido, como Manoel da Costa Ataíde, teria exercido tal função.

Mais comum ainda era o fato de que mesmo um importante pintor como o reconhecido mestre, autor da pintura do forro da nave da Capela de São Francisco da Penitência de Ouro Preto, pintasse ou dourasse objetos menos grandiosos que não forros ou retábulos de igrejas e capelas. Ataíde também pintou ou fez douramentos em cadeiras, esquifes e nadores [sic] para procissão (ARAÚJO, 2005, p. 209).

Assim, no âmbito da produção artesanal no contexto mineiro do século XVIII, é possível entrever uma "complementaridade entre a grande ideia de totalidade artística, de diálogo entre distintas manifestações e as circunstâncias em que se exerceram os trabalhos artesanais" (BRANDÃO, 2009, p. 63).

A partir de 1755, entretanto, com as consequências do terremoto havido em Lisboa, a grande demanda por oficiais para a reconstrução da cidade proporcionou algumas modificações na regulamentação das profissões. Em 1767, o novo "Regimento do Offício de Carpinteiros de Móveis e Sembrage" promoveu a reunião dos ofícios de carpinteiros e marceneiros (carpinteiros de móveis) em uma única profissão, colocando fim aos frequentes embates e respondendo à diversidade dos trabalhos então executados pelos oficiais que trabalhavam a madeira (BRANDÃO, 2013, p. 410-411). E já na primeira metade do século XIX, no contexto da América portuguesa, aumenta significativamente o número de carpinteiros de móveis e samblagem, de entalhadores e de marceneiros, sobretudo entre os artífices brasileiros, resultando, consequentemente, na diminuição do número de mestres portugueses.

Nesse século aparecem também alguns marceneiros de outras nacionalidades, alemães, franceses e ingleses, estes mais comerciantes 
de móveis que propriamente artífices. Alguns escravos e outros forros também aparecem como marceneiros ou carpinteiros de móveis. [...] Nas cidades os mestres estrangeiros e brasileiros tomam escravos como ajudantes que, aprendendo o ofício e tornando-se hábeis marceneiros, tornam-se rivais de seus mestres [...] (CANTI, 1989, p.181).

Convém lembrar também que, em Minas Gerais, o ambiente de produção artística era peculiar e se distinguia daquele conformado em Portugal. Uma das principais diferenças entre tais "culturas artísticas" foi sobretudo o "espírito inquieto" da vida mineira, que impulsionou seus artistas em direção à experimentação (DANGELO, 2014, p. 10). Já Bazin (1963, p. 77) sublinhava como a inventividade no trabalho artístico mineiro contribuiu para o rompimento com determinados modelos até então correntes no ambiente da Colônia: "É em Minas que começa a produzir-se a ruptura com esse espírito medieval, que tinha até então subsistido na colônia e que os monges alimentavam". Em seu entendimento, seria a região mineira, pela primeira vez, o palco de "puras especulações estéticas geradoras de formas criadas 'para a arte'”.

Outro fator tido como relevante para a liberdade na produção artística é a ausência de ordens religiosas regulares - as ordens primeiras -, em Minas Gerais, determinada pela administração real através do edito de 1711, renovado em 1715 e em 1721, que proibiu estritamente a fundação de qualquer convento e a presença de qualquer religioso regular naquela região em vista de um controle mais efetivo da coroa sobre as atividades mineradoras (BAZIN, 1963, p. 75). À inquietude e à independência em relação aos programas artísticos das ordens religiosas regulares cabe acrescentar a assimilação de outros modos e motivos que favoreceram a constituição da peculiaridade do ambiente artístico mineiro.

$\mathrm{Na}$ historiografia do mobiliário produzido no contexto luso-brasileiro nos séculos XVIII e XIX, são recorrentes as menções às suas características híbridas. A presença deste hibridismo se refere tanto à sobreposição de elementos de períodos históricos distintos quanto à combinação de modelos e matrizes provenientes de diferentes regiões. Robert Smith (1968, p. 285) considera este um traço característico do mobiliário português no século XVIII. Em seu entendimento, embora tenha perdido muito de sua originalidade naquele período com a assimilação de "modismos" advindos de Paris e Londres, 
o móvel português não se ateve à simples imitação de motivos estrangeiros, mas os combinou entre si, muitas vezes sem compromissos cronológicos. Do mesmo modo, no mobiliário em uso na América portuguesa nos Setecentos e princípio dos Oitocentos, além da persistência de peças características dos Seiscentos, e da mescla de elementos de diferentes épocas, ocorre ainda a combinação das características da produção artística e moveleira da Inglaterra, França, Holanda e do Oriente. Notadamente, são essas as mesmas regiões citadas por Zemella (1990, p. 79) como originárias dos produtos importados presentes no comércio que alcançava a região de Minas Gerais.

E, de fato, é relevante o papel exercido pelo comércio marítimo português para o contato com as criações artísticas da França, e em especial da Inglaterra, que repercutem na suntuária lusitana no início do século XVIII (BAYEUX, 1997, p. 47). As características inglesas no mobiliário português no início dos Setecentos são bastante evidentes e se devem tanto ao intercâmbio comercial quanto aos tradicionais laços políticos entre os dois reinos, consolidados desde a aliança Lancaster, e que perdurariam por todo o século. Some-se a isto o contato com modelos orientais:

As preciosidades da China e das Índias, os tecidos e os móveis orientais afluem a Portugal. O intercâmbio de artífices entre a metrópole e as colônias orientais estimula o interesse geral pela manufatura de origem exótica (RODRIGUES, 1968, p. 54).

Trasladadas à Capitania de Minas Gerais, essas características serão incorporadas no âmbito do já referido hibridismo e promoverão o aparecimento de determinadas "especificidades regionais" no feitio das peças de mobiliário. Tilde Canti (1980) enumera uma série de características de cunho regionalista presentes na produção de móveis mineiros. Dentre os exemplos típicos da região citados pela autora, merecem destaque os bufetes de pernas de lira; os bancos com caixa, ou "arcas-bancos", peculiares ao mobiliário denominado "mineiro-goiano"; as "camas de galeria", que, executadas no século XVIII e permanecendo em uso até princípios do XIX, conservavam características dos leitos seiscentistas portugueses, porém, muitas vezes com o acréscimo de elementos decorativos inexistentes em Portugal. Também a respeito das peculiaridades da produção mineira, Bayeux (1997, p. 72) destaca a ampla difusão do estilo Sheraton, executado sobretudo em Minas Gerais já na pri- 
meira metade do século XIX. Para a autora, a adaptação das características do mobiliário inglês às condições locais permitiria interpretações de caráter regional que resultariam no chamado "Sheraton Brasileiro".

Mas o regionalismo, compete lembrar, exibe também características oriundas da produção moveleira do Norte de Portugal, em particular a partir de meados do século XVIII. Em leitos mineiros fabricados neste período, Tilde Canti identifica elementos comuns àqueles portugueses do século anterior e que, portanto, serão nomeados "móveis tardios". Mas além destes, adverte,

[...] há também os que apresentam as balaustradas e colunas que sustentam o dossel recortadas na grossura da madeira, sem torneados, de mais fácil execução pelos que não possuíam o torno, e que classificamos como móveis rústicos (CANTI, 1980, p. 129).

A permanência no Norte de Portugal da conformação dos leitos seiscentistas com colunas e balaustradas torneadas e frontão de barra entalhada até meados do século XVIII é associada pela autora à origem dos "leitos e catres tardios executados no interior do Brasil, sobretudo em Minas Gerais". Isto se daria "devido ao grande número de mestres marceneiros e outros oficiais do Norte de Portugal [...] que se localizaram naquela região" (CANTI, 1980, p. 130). Mas, além dos leitos, também no feitio de bufetes se observam tais influências dos móveis seiscentistas procedentes do Norte de Portugal, especialmente do móvel minhoto, que contribuem para a caracterização do regionalismo mineiro. São os chamados bufetes de pernas de lira, isto é, com as pernas recortadas na grossura da madeira.

Os bufetes de pernas de lira, usados em Minas Gerais e Goiás durante todo o séc. XVIII, principalmente na sua segunda metade, são típicos dessa região, formando um verdadeiro estilo tardio mineiro-goiano, calcado nos móveis daquela região portuguesa. (CANTI, 1980, p. 138).

\section{CONSIDERAÇÕES FINAIS}

Em vista de tais ponderações, fica claro que o estudo do mobiliário produzido em Minas Gerais no século XVIII e início do XIX não pode ser reduzido a uma mera tentativa de classificação estilística. Ele requer, dentre outros aspectos, que se lance luz sobre as condições de sua produção, sobre os agentes e fatores determinantes que atuaram no seu feitio e as origens de suas carac- 
terísticas formais e estilísticas. Ou seja, o que aqui se procurou destacar é a relevância de incluir nos debates as peculiaridades do ambiente sociocultural constituído na Capitania, o papel desempenhado pelas trocas e pela atividade comercial para a circulação de modelos artísticos, a procedência e formação dos oficiais, assim como a imbricação das funções por eles desempenhadas com os respectivos reflexos na produção das peças. Deste modo, evidencia-se que sob a denominação "móvel colonial mineiro" é possível descortinar uma complexa rede de relações que contribuem para a melhor compreensão do universo das artes na América portuguesa.

\section{REFERÊNCIAS}

ARAUUJO, Jeaneth Xavier de. Artífices na Vila Rica setecentista: possibilidades de pesquisa. Encontro de história da arte - IFCH/Unicamp. Campinas, p. 202-209, 2005. Disponível em: <http:// www.unicamp.br/chaa/eha/atas/2004/DE\%20ARAUJO,\%20Jeaneth\%20Xavier\%20-\%20IEHA. pdf $>$. Acesso em: 30 nov. 2016.

BAYEUX, Glória. O móvel da casa brasileira. São Paulo: Museu da Casa Brasileira, 1997.

BAZIN, Germain. O Aleijadinho e a escultura barroca no Brasil. Rio de Janeiro: Record, 1963.

BLUTEAU, Raphael. Vocabulário portuguez e latino: aulico, anatomico, architectonico, bellico, botanico. Coimbra: Collegio das Artes da Companhia de Jesus, 1728.8 v. Disponível em: <http:// www.brasiliana.usp.br/search?filtertype $={ }^{*} \&$ filter $=$ bluteau\&submit_search-filter-controls_ad$\mathrm{d}=$ Buscar $>$. Acesso em: 20 ago. 2016.

BRANDÃO, Angela. Das pontes aos castiçais: a produção de mobiliário artístico em Minas Gerais do século XVIII e os ofícios mecânicos. Revista Científica da Faculdade de Artes do Paraná, Curitiba, v. 4, n. 2, p. 50-66, jul./dez. 2009. Disponível em: <http://www.fap.pr.gov.br/modules/ conteudo/conteudo.php?conteudo=139>. Acesso em: 20 ago. 2016.

. Sobreposição de tarefas: uma leitura do dicionário de Judith Martins. Arte e suas instituições, Rio de Janeiro, 2013. p. 395-413.

CANTI, Tilde. O móvel no Brasil: origens, evolução e características. Rio de Janeiro: Cândido Guinle de Paula Machado, 1980.

O móvel do século XIX no Brasil. Rio de Janeiro: Cândido Guinle de Paula Machado, 1989.

COSTA, Iraci del Nero da; LUNA, Francisco Vidal. Minas colonial: economia \& sociedade. São Paulo: Pioneira, 1982.

COSTA, Lucio. Notas sobre a evolução do mobiliário luso-brasileiro. Revista do Serviço do Patrimônio Histórico e Artístico Nacional, Rio de janeiro, n. 3, 1939. p. 149-162.

CUNHA, Luiz Antônio. O ensino de ofícios artesanais e manufatureiros no Brasil escravocrata. São Paulo: Editora da Unesp, 2000.

DANGELO, André G. D. A cultura arquitetônica em Minas Gerais e seus antecedentes em Portugal 
e na Europa: arquitetos, mestres-de-obras e construtores e o trânsito de cultura na produção da arquitetura religiosa nas Minas Gerais setecentistas. 2006. 490 f. Tese (Doutorado em História Social da Cultura) - Faculdade de Filosofia e Ciências Humanas, Universidade Federal de Minas Gerais, Belo Horizonte, 2006.

José Coelho de Noronha, arquiteto: um mestre lisboeta nas Minas Gerais Setecentistas. Actas do IV Congresso de História da Arte Portuguesa em Homenagem a José-Augusto França, Lisboa, 2014, p. 9-15, nov. 2014. Disponível em: <http://www.apha.pt/wp-content/uploads/docs/ Actas\%20IV\%20CHAP\%20final.pdf>. Acesso em: 20 ago. 2016.

DIAS, Hélcia. O mobiliário dos inconfidentes. Revista do Serviço do Patrimônio Histórico e Artístico Nacional, Rio de Janeiro, n. 3, p. 163-172, 1939.

FERNANDES, Cybele V. Neto. Labor e arte, registros e memórias. As teias do fazer artístico no espaço luso-brasileiro. Actas VII Colóquio Luso-Brasileiro de História da Arte, Porto, 2005, p.109$118,2007$.

FLEXOR, Maria Helena Ochi. Oficiais mecânicos da cidade de Salvador. Salvador: Prefeitura Municipal de Salvador, 1974.

Mobiliário brasileiro: Bahia. São Paulo: Espade, 1978.

Os oficiais mecânicos na cidade notável do Salvador. Actas VII Colóquio Luso-Brasileiro de História da Arte, Porto, 2005, p. 373-383, 2007.

Mobiliário baiano. Brasília: IPHAN / Programa Monumenta, 2009.

LIMA JÚNIOR, Augusto de. A capitania das Minas Gerais. São Paulo: Edusp, 1978.

MARTINS, Judith. Dicionário de artistas e artífices dos séculos XVIII e XIX em Minas Gerais. Rio de Janeiro: IPHAN, 1974. $2 \mathrm{v}$.

MENESES, José Newton Coelho. “Mecânicos" e "Mesteres”.Trabalho, cotidiano e poder local no final do Antigo Regime português - Minas Gerais e Lisboa - 1750-1808. Revista do Instituto Histórico e Geográfico Brasileiro, Rio de Janeiro, n. 421, p. 233-259, 2003. Disponível em: <https:// drive.google.com/file/d/0B_G9pg7CxKSsMmgySUF5a3h4SDQ/view>. Acesso em: 30 nov. 2016.

OLIVEIRA, Myriam Andrade Ribeiro de. Entalhadores bracarenses e lisboetas em Minas Gerais setecentista. Actas VII Colóquio Luso-Brasileiro de História da Arte, Porto, 2005, p. 423-430, 2007.

RODRIGUES, José Wasth. Mobiliário. Rio de Janeiro: Ed. de Ouro, 1968.

Móveis antigos de Minas Gerais. Revista do Serviço do Patrimônio Histórico e Artístico Nacional, Rio de Janeiro, n. 7, p. 79-98, 1943.

SANTOS, José de Almeida. Mobiliário artístico brasileiro. São Paulo: Elvino Pocai, 1944. 3 v.

SMITH, Robert Chester. The art of Portugal. London: Weidenfeld \& Nicolson, 1968.

VASCONCELOS, Salomão de. Ofícios mecânicos em Vila Rica durante o século XVIII. Revista do Serviço do Patrimônio Histórico e Artístico Nacional, Rio de Janeiro, n. 4, p. 331-360, 1940.

VASCONCELLOS, Sylvio de. Vila Rica: formação e desenvolvimento, residências. São Paulo: Perspectiva, 2011. 
ZEMELLA, Mafalda P. O abastecimento da capitania das Minas Gerais no século XVIII. São Paulo: HUCITEC, 1990.

Artigo recebido em: 30/08/2016

Artigo aprovado em: 03/07/2017 